\title{
Clasificación de Ecosistemas Intelectuales
}

Christian Álvarez-Rojas ${ }^{1}$

\section{Introducción}

Dentro de los Estudios Eidéticos resulta necesario clasificar y comparar no solo las ideas, sino también realizar el mismo ejercicio teórico con los espacios geográficos en donde ellas circulan, mutan y se producen. En este sentido Eduardo Devés ha acuñado la expresión «Ecosistemas Intelectuales» (también «icosist») para referirse a «la interacción de un conjunto de organismos intelectuales a través de décadas y siglos (ideas, inteligencias, especialmente no de forma exclusiva figuras intelectuales, y organizaciones o agrupaciones ocupadas de lo eidético) en un espacio físico y simbólico con el cual interactúan» (2021, p. 18).

La conjunción de factores institucionales, culturales, geográficos e históricos, es decir, de aspectos que dependen de las voluntades humanas pero que también las sobrepasan y determinan, configura una especificidad de los EI que se reflejará en entidades, dinámicas, y campos como los entiende Pierre Bourdieu. Los EI, de paso, permiten explicar la noción de «campo» usada en sociología, ampliando a su vez el alcance temporal y geográfico de su acepción, sin ceñirse a las disciplinas académicas universitarias e incluyendo una cantidad mayor de factores que la competencia individual entre especialistas por prestigio, poder o confirmación teórica.

En este punto, Eduardo Devés plantea una primera clasificación:

[I]nteresa distinguir los pequeños de la oralidad, pre-urbanos y de aldeas, entre los cuales las ideas circulan solo instaladas en los cerebros-mentes, de los de lectoescritura y urbanos, entre los cuales las ideas circulan predominantemente en estado de latencia, envasadas en tabletas, libros o papiros y más recientemente de modo virtual. Lo señalado anteriormente apunta a caracterizar los EIs mediante criterios que permitan entender las formas y vías de circulación. Interesa, por otra

\footnotetext{
1 Dr. (C) en Estudios Americanos. Instituto de Estudios Avanzados, Universidad de Santiago de
} Chile. ORCID ID: 0000-0001-9800-1834 
parte, distinguir también los EIs con alta y baja receptividad a las ideas venidas desde el exterior. Muchos poseen una institucionalidad encargada del import/export, que actúa con criterios de selectividad, e incluso han creado organismos de seguridad eidética. (p. 19)

Esta clasificación puede ser reconstruida según un criterio de «soporte eidético», es decir, a partir del medio por el cual las ideas se crean, mutan y se difunden, siendo la escritura un factor no solo crucial respecto a la creación de un acervo y conciencia históricos, sino además porque aumenta las propias posibilidades creativas, ya sea porque libera las facultades cognitivas antes puestas al servicio de la memoria o por la creatividad posibilitada en la escritura. La consecuencia directa que se menciona es la circulación y recepción de ideas, que aumenta nuevamente las posibilidades creativas, haciendo emerger la distinción entre receptores y emisores, con posibles limitaciones a sus acciones según los intereses de las comunidades a las que pertenezcan.

A partir de esta clasificación inicial, propongo a continuación otras clasificaciones posibles, manteniendo el interés en la explicación del distinto grado de circulación de ideas, considerando al mismo tiempo estos criterios como una herramienta metodológica sin pretensiones de agotar las posibilidades de los EI realmente existentes, sino más bien como posibilidades de análisis «en principio» que permitan compararlos aun cuando bajo un criterio, como el lectoescritural, pudiera parecer un ejercicio anacrónico e infructífero.

\section{Clasificaciones de Ecosistemas Intelectuales}

\section{Según soporte eidético: Oral/Escrito.}

Si bien el criterio es dicotómico, se debe considerar la presencia y permanencia de intelectualidades orales dentro de EI letrados, como ha ocurrido en las periferias globales colonizadas, en donde, aún las personas que actúan como intelectuales indígenas letradas, lo hacen a partir de una trayectoria eidética que ha respondido por siglos a la oralidad. Esta presencia implica, potencialmente, un impacto en el tipo de producción letrada, incorporándole atributos axiológicos de distinto 
énfasis: la oralitura como propuesta en los estudios literarios, o el valor del testimonio y la memoria como criterios de verdad, sea para el razonamiento ético o epistemológico, defendido en enfoques decoloniales o críticos con el racionalismo discursivo moderno.

Cabe una opción teóricamente intermedia para la iconografía, icosists donde existe creación de imágenes que requieren ser decodificadas, cuya interpretación permite la transmisión de conocimientos con fines pedagógicos, proselitistas o políticos. En el imperio incaico los quipu, sistema de contabilidad a partir de nudos, también podían almacenar información sobre las jerarquías políticas (Urton \& Brezine, 2005), o incluso se ha propuesto la existencia de contenidos literarios en sus versiones en tiempos de la Conquista (Domenici \& Domenici, 1996). Su producción textil de tocapus forma "parte de un sistema de registro, almacenamiento y comunicación durante el Tahuantinsuyu» (Gentile, 2010).

El uso del tejido como expresión de ideas, especialmente sobre jerarquías sociales e información genealógica, también ha sido usado en la cultura mapuche (Alvarado, 2002), hawaiana y china antigua (Jakobsen, 1983).

Otra expresión de ideas a nivel iconográfico ocurre en Gandhara, durante el reinado de Kanishka (120-144 DC), quien al convertirse al budismo promueve la actividad artística y filosófica que genera innovaciones iconográficas para representar a nivel visual y simbólico las distintas etapas de la vida de Siddhartha Gautama y promover su doctrina (Lira Latuz, 2009).

\section{Según irradiación}

A diferencia de la clasificación anterior, que puede considerarse autónoma, además de referirse a una variable deíctica como el soporte mediante el cual se traspasan y crean ideas, este criterio es relativo. Depende de la comparación entre EI distintos, o bien de un mismo EI en distintos momentos a través del tiempo. Un EI A irradia más que un EI B (siendo A y B distinciones espaciales y/o temporales) si emite ideas en mayor cantidad, con mayor impacto o con mayor especificidad. 
Estos criterios son complementarios, medibles asimismo según indicadores relativos, como cantidad de publicaciones, cantidad de referentes intelectuales individuales o colectivos- o cantidad de denominaciones eidéticas. Por ejemplo, la existencia de expresiones eidéticas como «cepalismo» o «arielismo», denotan que hay una masa crítica de ideas con una novedad considerable respecto a sus antecesoras, así como un público externo a los EI en que se originan capaz de reconocerlas.

Para trabajar en este criterio resulta útil la noción de «antenas retransmisoras» (Devés, 2021, p. 357), a la que agregamos las emisoras y receptoras: hay EI que emiten, retransmiten y reciben más ideas. Se vuelven más susceptibles de ser detectados por otras antenas receptoras, o bien, ser imperceptibles y quedar diluidos en el ruido de fondo de la producción intelectual global.

Otro factor relevante es la creatividad, siendo los EI capaces de generar expresiones eidéticas originales más susceptibles de ser detectados, aun cuando su emisión sea más débil: las ideas liberacionistas latinoamericanas circulan más que las versiones locales de la fenomenología de Husserl o del positivismo. Los períodos de mayor irradiación de un mismo EI comparado con momentos de menor impacto pueden entenderse como un «boom», donde, tal como la explosión de una supernova, la estrella emite una cantidad de energía que le hace ser mucho más visible por un lapso minúsculo en comparación a su existencia previa y posterior.

La irradiación, al menos en términos metodológicos, es inseparable de EI con lectoescritura, dada la extrema dificultad para rastrear la circulación de ideas en sociedades orales, más allá de elementos míticos transmitidos a través del tiempo (d'Huy, 2016). En EI iconográficos, se constata, por ejemplo, la emisión del Imperio Macedonio sobre Gandhara (Lira Latuz), siendo, sin embargo, imprecisa la transmisión de ideas específicas. 


\section{Según autoconciencia}

Esta clasificación se refiere a la noción de ser un polo de desarrollo intelectual distinto a otros, potencialmente rival de otros. Se puede entender como una gradiente entre los polos baja/alta, con autonomía para cada Ecosistema Intelectual. Por «autoconciencia» propongo una reformulación de la constatación hecha desde los estudios eidéticos sobre el Pensamiento Periférico (Devés, 2017): toda sociedad se ha creído el «ombligo del mundo», lo que se ha constatado como falso cuando es enfrentada y dominada por un poder externo.

La noción «autoconciencia» analiza este hecho con énfasis comparativo entre Ecosistemas Intelectuales en tiempo y espacio, es decir, periféricos, del centro, pero también en el desarrollo de un mismo EI a través del tiempo, en su proceso de descentramiento.

\section{Según autoestima}

En esta clasificación busco sintetizar el tratamiento que Eduardo Devés realiza sobre las sensibilidades como factor que condiciona la producción eidética (2017). En Pensamiento Periférico. Una tesis interpretativa global, las sensibilidades «opera[n] como caldo de cultivo, como una especie de catalizador al interior de las redes y del campo intelectual» (p. 729). Enfatizando los sentimientos de inferioridad, de revancha o decadencia al constatar el descentramiento del mundo ya mencionado. Con la repetición de la gradiente baja/alta, propongo que las sensibilidades, para el estudio comparativo de EI, se puedan agrupar según autoestimas bajas o elevadas, es decir, apuntando a la percepción subjetiva dentro de un EI de que se está en una posición favorable para desarrollar ideas, que estas ideas son importantes y merecen ser escuchadas, en comparación con momentos en donde ocurra lo contrario.

Los momentos de «boom» mencionados en la clasificación de irradiación son especialmente propensos a la autoestima alta de los EI, lo que, sin embargo, no les vuelve sinónimos: un ecosistema de baja autoestima, como uno que haya sufrido 
una derrota militar o una crisis económica severa, podría en principio irradiar más que uno en buena autoestima. París, aun en momentos de autodeclarada decadencia, emite/es más percibido globalmente que una optimista La Paz de inicios del siglo XXI.

\section{Según complejidad de primer orden}

En esta clasificación se utiliza la nomenclatura de la Teoría General de Sistemas en relación con la distinción entre un sistema como todo distinto de sus partes (Arnold \& Osorio, 1998). Un EI de menor complejidad será uno con menos partes respecto a otro o a sí mismo en otro tiempo. Por partes podemos entender a la cantidad de actores participantes, ya sea como individuos o instituciones. Es un criterio preferentemente cuantitativo que apunta a responder cuestiones descriptivas del tipo: cuántas universidades hay en el EI A respecto a EI B, cuántas personas son reconocidas como intelectuales, cuántos think tanks, cuántas iglesias, y organizaciones comparables en la generación, almacenamiento y difusión de ideas.

Las partes pueden ser jerarquizables: una universidad, un concejo de ancianos o una iglesia, tendrán una prioridad en la generación de ideas según cada EI o en cada momento, respecto a individuos particulares $\mathrm{u}$ otras organizaciones. Una parte puede dirigir a las otras, ya sea directamente, en el caso de EI tendientes al totalitarismo, o por influencia según el prestigio, como ocurre con la difusión de los paradigmas científicos (Kuhn, 2013).

\section{Según complejidad de segundo orden}

Esta clasificación se refiere a una perspectiva sistémica con enfoque de diferenciación funcional, donde la complejidad Baja/Alta está dada por el nivel de distinción dentro del EI. Es una clasificación preferentemente cualitativa. Tomando, provisoriamente y para efectos metodológicos, a los EI como un sistema funcionalmente diferenciado, su complejidad se reflejará en cómo se diferencia de 
su entorno, compuesto por el espacio geográfico y por otros EI, y cómo estas distinciones se replican en su interior. Niklas Luhmann lo plantea de la siguiente manera:

La diferenciación del sistema no es otra cosa que la repetición de la diferencia entre sistema y entorno dentro de los sistemas. El sistema total se utiliza a sí mismo como entorno de la formación de sus sistemas parciales. Alcanza con esto, en el nivel de los subsistemas, un grado más alto de improbabilidad al fortalecer los efectos de filtración frente a un entorno que es, finalmente, incontrolable. De esta manera, un sistema diferenciado ya no consta propiamente de un determinado número de partes y de relaciones entre las partes, sino, más bien, de una mayor o menor cantidad de diferencias operativamente utilizables entre sistema y entorno. Estas diferencias reconstruyen, en distintas líneas de intersección, al sistema total como la unidad de partes del sistema y su entorno. (Luhmann, 1998, p. 31-2)

Las funciones no son jerarquizables, una no puede dirigir a otra ni menos al conjunto. No existe un centro sino una multiplicidad de subsistemas que han coevolucionado y operan mediante autopoiesis, según la célebre recepción que Luhmann hizo del trabajo de Humberto Maturana y Francisco Varela.

Un ejemplo de la perspectiva funcional sistémica es el análisis del cuerpo humano (Moeller, 2012), donde desde un análisis de complejidad de primer orden el cuerpo se compone de órganos. Los órganos pueden ser transplantados, cumplen funciones distintas e incluso son jerarquizables: se puede extirpar el apéndice pero no el corazón. Desde un análisis de complejidad de segundo orden el cuerpo es un sistema con subsistemas como el circulatorio, endocrino, nervioso, digestivo, etc. Ningún sistema es más importante que otro ni puede dirigir al resto, ya que han coevolucionado. No se puede «separar» al sistema circulatorio del nervioso, ya que hay órganos que cumplen funciones distintas en cada sistema. Incluso, comparando entre especies distintas, una medusa no es «incompleta» por no tener sistema visual. Cada sistema es una unidad coherente según su trayectoria evolutiva.

A diferencia de Luhmann, no propongo a la diferenciación funcional como una «superación» de una perspectiva todo/partes. Para el análisis de Ecosistemas 
Intelectuales son métodos complementarios en tanto plantean diferencias de énfasis.

Como ejemplos posibles de la comparación de complejidad de EI, un EI A tiene un sistema de enseñanza que implica la creación de acervo e investigación de conocimientos nuevos. B tiene un sistema de enseñanza fundado en la capacitación laboral. A distingue la investigación de la teología con instituciones separadas; en B forman parte de un continuo con las mismas instituciones. La cantidad o tipo de instituciones (universidades, iglesias, think tanks) puede estar indiferenciada en una misma función, como la educación o el poder político, o bien estar diferenciada entre funciones aún más variadas, como la religión, creación de identidad cultural, recreación, práctica deportiva o generación de empleo.

\section{Conclusiones}

A partir de la clasificación oral/escrita, entendida como un criterio autónomo y estructural, en tanto define el soporte de la creación y transmisión de ideas, se pueden plantear criterios que también sean relativos, a partir de la comparación de Ecosistemas Intelectuales distintos o consigo mismos en el tiempo, y apuntando a otros factores que inciden en la expresión eidética, somo las sensibilidades, las posibilidades de irradiación, o la composición de los icosist. Las clasificaciones propuestas, si bien no pretenden agotar las posibilidades, sí reclaman la necesidad de comprender a los EI como unidades de análisis bajo criterios múltiples, siguiendo la advertencia de Ludwig Wittgenstein sobre los límites del lenguaje como límites del mundo, y a Santo Tomás en que combinar y separar son aspectos fundamentales del entendimiento (Wippel, 1978).

Siguiendo el programa de investigación de los estudios eidéticos, estas clasificaciones corresponden a directrices laxas para el estudio de casos empíricos, a criterios utilitarios para analizar de forma complementaria y múltiple la producción, circulación y conservación de ideas, en este caso, tomando como unidad de análisis el Ecosistema Intelectual. 


\section{Bibliografía}

Alvarado, M. (2002). "El esplendor del adorno. El poncho y el chañuntuku". Catálogo Hijos del Viento. Arte de los pueblos del sur. Siglo XIX, 50-54. Buenos Aires: Fundación PROA.

Arnold, M. \& Osorio, F. (1998). "Introducción a los conceptos básicos de la teoría general de sistemas". Cinta de Moebio 3: 40-49.

Devés, E. (2017). Pensamiento periférico. Una tesis interpretativa global. Santiago de Chile: Ariadna.

(2021). La circulación de las ideas de América Latina-Caribe por el mundo, 1970-2000. Santiago de Chile: Ariadna.

d'Huy, J. (2016). “The evolution of myths". Scientific American 315(6): 62-69. doi:10.1038/scientificamerican1216-62.

Domenici, V. \& Domenici, D. (1996). "The talking knots of the Inka”. Archaeology 49(6).

Gentile, M. (2010). "Tocapu: unidad de sentido en el lenguaje gráfico andino". Espéculo. Revista de estudios literarios, 45.

Jakobsen, L. E. (1983). "Use of knotted string accounting records in old Hawaii and Ancient China”. The Accounting Historians Journal 10(2). 53-61.

Kuhn, T. (2013). La estructura de las revoluciones científicas. México D. F.: FCE.

Lira Latuz, C. (2009). "Mito e iconografía. La representación antropomorfa del Buda Sakyamuni”. En Lira Latuz, C. (Ed.) A la sombra del manzano en flor. Indagaciones estéticas en torno al budismo (39-80). Santiago de Chile: Pontificia Universidad Católica de Chile. Facultad de Filosofía. Instituto de Estética.

Luhmann, N. (1998). Sistemas sociales. Lineamientos para una teoría general. Barcelona: Anthropos. 
Moeller, H. G. (2012). The radical Luhmann. New York: Columbia University Press.

Urton, G. \& Brezine, C. (2005). "Khipu Accounting in Ancient Peru". Science, 309(5737): 1065-1067. doi:10.1126/science.1113426

Wippel, J. F. (1978). "Metaphysics and "Separatio" According to Thomas Aquinas". The Review of Metaphysics 31(3): 431-470.

Wittgenstein, L. (2001). Tractatus Logico-Philosophicus. Londres: Routledge. 